\title{
Pharmacological Studies of Oxalis pes-caprae L.
}

\author{
Syeda Naila*, Muhammad Ibrar
}

\section{Syeda Naila*, Muhammad Ibrar}

Department of Botany, University of Peshawar, Peshawar, Khyber Pakhtunkhwa, PAKISTAN.

Correspondence

\section{Syeda Naila}

Department of Botany, University of Peshawar, Peshawar, Khyber Pakhtunkhwa, PAKISTAN.

Phone no : +923369163696

E-mail: syedanaila13@gmail.com

\section{History}

- Submission Date: 25-01-2018;

- Review completed: 06-03-2018;

- Accepted Date: 03-05-2018

DOI : 10.5530/pj.2018.4.117

Article Available online

http://www.phcogj.com/v10/i4

\section{Copyright}

(c) 2018 Phcog.Net. This is an openaccess article distributed under the terms of the Creative Commons Attribution 4.0 International license.

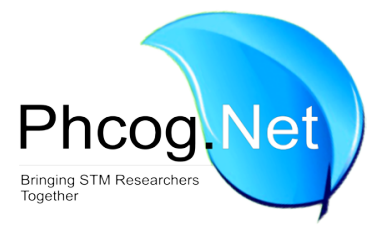

\begin{abstract}
Background: Oxalis pes-caprae is also called as "sourgrass" or soursob. The roots, stems and leaves of Oxalis pes-caprae have high medicinal values and have the function of antiinflammatory and analgesia, clearing heat, removing toxicity. In present study Oxalis pescaprae belonging to family oxalidaceae evaluated for pharmacological activities like cytotoxicity, phtotoxicity, antibacterial and antifungal bioassays. Materials and Methods: Cytotoxic activity was performed by brine shrimp bioassay using methodology of Atta-ur-Rahman et al., 2001. The phytotoxic activity was investigated by applying Lamna minor (as test species) following Atta-ur-Rahman et al., 2001.Anti-bacterial screening was conducted following Rathan (2000). Anti-fungal screening was carried out using agar well diffusion method following Perez et al. (1990) and Atta-ur-Rahman et al. (1991). Results: Its ethanolic extract showed highly significant $(100 \%)$ cytotoxicity with LD $_{50} 8.98$ at 1000 ppm. Lemna minor phytotoxicity assay showed that 0 . pes-caprae chloroform extract showed $90 \%$ inhibition at 1000 ppm with $\mathrm{FI}_{50} 0.1048$. Antibacterial bioassays showed that all the samples of the plant were significant against Xanthomonas, Clavibacter machengnitis and Bacillus at 1000, 1500 and 2500 ppm doses. Dose dependent antifungal activities against test species (Aspergillus flavus, Penicillium and Fusarium solani) were noticed for all the extracts at 100 and 1000 ppm. Conclusion: Pharmacological potentials showed that this plant can be used in upcoming time for extracting numerous active constituents for their pharmacological preparations.

Key words: Pharmacology, Oxalis pes-caprae, Whole plant, Cytotoxic activity, Phytotoxic activity, Antifungal activity, Antibacterial activity.
\end{abstract}

\section{INTRODUCTION}

Biochemical, chemical, physical and biological characteristics of drug and exploration of novel drugs from natural sourcesare studied in field of pharmacognosy. ${ }^{1}$ The subjects of Botany, Chemistry and Pharmacology are involved in the study of medications from plant sources. ${ }^{2}$ Pharmacognostical research consists of phytochemistry, microbiology, biosynthesis, biotransformations, chemotaxonomy and other biological and chemical sciences. ${ }^{3}$ Measure of the strength or potency of the functional constituents or indicator compound is known as standardization. It's used to mention the batch-to-batch consistency of effective ingredients instead of the intensity and reliability of the pharmacological effects and within the industry and several regulatory agencies has been the matter of extreme discussion. ${ }^{4}$

Pharmacognosist Professors Jerry L. McLaughlin and colleagues established simple brine shrimp lethality " 'bench top" bioassay, ${ }^{5}$ that proved suif to regulate the diagnosing of anti-tumours and cytotoxics compound from plant. ${ }^{6}$ Phytotoxic activity is the initial weedicide bioactivity of natural products for screening potential phytotoxic plants. ${ }^{7}$ A variety of novel antimicrobial drugs in the recent period have been developed by pharmaceutical industries but at the same time opposition to these drugs by microbes has built up. Generally, bacteria exhibit the genetic capability to transfer and develop resistance to drugs used as healing agents. ${ }^{8}$ Use of synthetic fungicides for control of fungal infestations is common, but its use is constrained because of the noxious effects on organism's healthiness and on surroundings. ${ }^{9}$

Oxalis pes-caprae L.is perennial, herbaceous plant withbulbiferous andunderground stem.It is native to South Africa. It is naturalized to West Europe and Mediterranean region, South West Asia, North Africa, Turkey and Iran. In the plains having shady places, it is found as a weed..$^{10}$ The plant is edible and in moderate quantity is unhazardous. This plant also a traditional constituent in recipe i.e. water blommet jiebredie (water flowers stew) in South Africa. ${ }^{11}$ In several traditions it is used in folk medicines, as foods and for oxalic acid. For treating tapeworm and may be other worms, raw bulbs are used. It is also utilized as diuretic. Fleshy underground runners are also eaten with milk. ${ }^{12}$ Yellow dye is obtained from the golden petals. ${ }^{13}$ The roots, stems and leaves of Oxalis pes-caprae have high medicinal values and 
have the function of anti-inflammatory and analgesia, clearing heat, removing toxicity. ${ }^{14}$

\section{MATERIALS AND METHODS}

\section{Plant Collection and Preservation}

Fresh collection of Oxalis pes-caprae at their flowering stagewas carried out from Department of Botany, University of Peshawar, Pakistan. Plant materials were cleaned, washed and garbled. Few fresh plants of Oxalis pes-caprae were pressed, dried, pasted on herbarium sheet and assigned voucher numbers (Bot. 20128 (PUP) and deposit in herbarium (Department of Botany, University ofPeshawar, Pakistan) for reference. Collection was dried in shade at about $25 \pm 3{ }^{\circ} \mathrm{C}$ and powdered with electric grinder. For protecting powder frommolds, insects attack andmoisture, these were stored inair tight bottles and used for various biochemicals and biological research studies.

\section{Extract Preparation}

In airtightbottles, $500 \mathrm{ml}$ of different solvents (ethanol, methanol, n-hexane, acetone, chloroform) and 100gm powder of plants were mixed and kept for 7 days with occasional shaking. After this extract was filtered and in rotary evaporators filtrates were dried.

\section{Pharmacology}

For measuring therapeuticpotential of Oxalis pes-caprae the following pharmacological studies were conducted.

\section{Cytotoxic Bioassay}

Cytotoxic activity was performed for ethanolic, methanolic, acetone, n-hexane and chloroform extractsof Oxalis pes-caprae bybrine shrimp bioassay using methodology of. ${ }^{15}$

\section{Requirements}

Artemia salina (shrimps eggs), sea salt solution (38g/L of distilledwater), illuminating source (lamp) to attractbrine-shrimp larvae, hatching tray with perforated partition, Pasture's pipettes, magnifying lens, micro pipettes $(5,50,500 \mu \mathrm{l})$, test samples, test tube stands, test tubes, ethanol, methanol, acetone, $\mathrm{n}$ - hexane and chloroform.

\section{Technique for Hatching}

Filtered brinesolution was put inhatching tray (rectangular dish $(22 \times 32 \mathrm{~cm})$. 2 unequalpartitions (perforated) were made in tray. $25 \mathrm{mg}$ brine shrimp eggs powder was scattered in smaller portion. The larger portion was remaining uncover and smaller was wrap with black paper. For hatching of eggs, tray was kept at room temperature. For illuminating open portion of tray, lamp was hanging over tray. The hatched napualli were viewed to move toward theenlightened portion.

\section{Preparation of Sample}

Sample was prepared by dissolving $20 \mathrm{mg}$ of extract in $2 \mathrm{ml}$ of solvent. To test tubes ( 3 test tubes /concentration) 5, 50 and $500 \mu$ l solution was transferred i.e. equivalent to 10,100 and $1000 \mu \mathrm{g} / \mathrm{ml}$ respectively. Solvents could evaporate overnight and to each test tube $5 \mathrm{ml}$ seawater solution $(38 \mathrm{~g} / \mathrm{L})$ was added and transferred 10 larvae with help of Pasteur pipettes. At room temperature $\left(25-27^{\circ} \mathrm{C}\right)$, test tubes were kept under illumination. Test tubes filled with brine solution and reference cytotoxic drug used for negative and positive controls respectively.

\section{Statistical Tests}

Numbers of dead and live napualli were counted after $24 \mathrm{hr}$. The data was analyzed through Biostat software to determine $\mathrm{LD}_{50}$ values. ${ }^{16}$

\section{Phytotoxic Bioassay}

The phytotoxic activity of ethanolic, methanolic, acetone, n-Hexane and chloroform extracts of Oxalis pes-caprae was investigated by applying Lamna minor (as test species) following. ${ }^{15}$

\section{Require Materials}

Distilled water, micropipettes (10-100 $\mu \mathrm{l}, 100-1000 \mu \mathrm{l})$, flask $250 \mathrm{ml}$, test samples (extracts), Lemna minor (test species), filter paper, oven, petri dishes, luminarflow hood, glass vials, E- medium, brush.

\section{Media Preparation}

For Lemna minor bioassay, E-medium was made from various mineral nutrients having known quantity (Table 1). First the salts were weighed in required quantity then dissolved in distill water and volume was made up to $1000 \mathrm{ml}$. By addition of $\mathrm{KOH}$, $\mathrm{pH}$ was adjustedbetween 5.5-6.00.

\section{Methodology}

Sample was prepared by dissolving $15 \mathrm{mg}$ of extract in $1.5 \mathrm{ml}$ of solvent and to sterilized petri dish (3 petri dishesfor each concentration) 5,50 and $500 \mu \mathrm{l}$ solutions were transferred i.e. equivalent to 10,100 and $1000 \mu \mathrm{g} / \mathrm{ml}$ respectively. Solvents could evaporate overnight in sterilized condition in laminar flow. To each petri dish $20 \mathrm{ml}$ E.medium was added. Petri dishes filled with E. medium alone and standard drug (Atrazine) used as negative and positive controls respectively. 10 plants of Lemna minor with two fronds were transferred to each petri dish. Numbers of frondswere counted on $3^{\text {rd }}$ and $7^{\text {th }}$ day of experiment. With reference to negative control, percent growth inhibition was noted by applying formula

$$
\% \text { Inhibition }=100-\frac{\text { Number of fronds in test sample }}{\text { Number of fronds in negative control }} \times 100
$$

\section{Statistical Tests}

Results for phytotoxicity were analyzed by using Biostat software to determine $\mathrm{FI}_{50}$ values. ${ }^{16}$

\section{Antibacterial Activity}

Anti-bacterial screening was conducted for ethanolic, methanolic, acetone, n- Hexane and chloroform extracts ofOxalis pes-caprae following. ${ }^{17}$

\section{Requirments}

Nutrient broth, test samples, nutrient agar, Laminar flow unit, Standard antibiotics (streptomycin), micropipettes, sterile cotton swab, petri dishes, test tubes, incubator, autoclave, filter paper discs, DMSO.

\section{Test Organisms}

Xanthomonas, Clavibacter machengnitis and Bacillus.

\section{Procedure}

Antibacterial activities of the plants were conducted by filter paper disc method as explained by. ${ }^{17}$ On nutrient broth, bacterial strains were cultured and before experiments incubated for $24 \mathrm{hr}$. Nutrient agar was melted, cooled to $40^{\circ} \mathrm{C}$ and transfer into sterilized petridishes. By using sterilized cotton swab, 4 to $8 \mathrm{hr}$ old bacterial culture was spread on surface of nutrient agar. Betweeneach streaking, turning the plate $60^{\circ}$ repeating the procedure thrice. Filter paper discs were placed in petridishes and to these discs sample extracts, four concentrations i.e. $100 \mathrm{ppm}, 1000 \mathrm{ppm}, 1500 \mathrm{ppm}$ and 2500ppm were applied. Other discs were filled with DMSO and 100ppm streptomycin used as negative and 
positive controls respectively. For $24 \mathrm{hr}$ the plates were incubated at $37^{\circ} \mathrm{C}$ and then noted for zones of inhibition.

\section{Antifungal Activity}

Anti-fungal screening of ethanolic, methanolic, acetone, n- Hexane and chloroform extract of Oxalis pes-caprae were carried out using agar well diffusion method following. ${ }^{18,7}$

\section{MATERIAL}

Seven days old fungal cultures, test samples, potato dextrose agar (PDA), Dimethyle sulphoxide (DMSO), petri dishes, cork borer, micropepites, autoclave, incubator, Laminar flow Unit (LFU), spirit, standard antibiotic (streptomycin), fungicide.

\section{Test Fungi}

Aspergillus flavus, Penicillium andFusarium solani.

\section{METHODOLOGY}

$25 \mathrm{ml}$ pre-sterilized PDA was poured in each pre-sterilized petridishes under sterile conditions and allowed to solidify. Wells of $6 \mathrm{~mm}$ diameter was made by sterile cork borer in media. To the wells, sample extract of two concentrations i.e. $100 \mathrm{ppm}$ and 1000ppm was added through micropipette. Next each petri dish was inoculated with $6 \mathrm{~mm}$ diameter piece of inoculumcut off from seven days old fungal culture. Media filled with DMSO and fungicide was used for negative and positive controls respectively. Petri dishes were incubated at $27^{\circ} \mathrm{C}$ for7 days. During incubation cultures were examined twice weekly. Growth in media was calculated by measuring growth ( $\mathrm{mm}$ ) of fungal strains loaded with DMSO, fungicide and sample. Percentage inhibition of fungal growth was calculated by following formula. ${ }^{19,20}$

$$
\% \text { Mycelia inhibition }=\frac{\mathrm{Gn}-\mathrm{Gt}}{\mathrm{Gn}} \times 100
$$

Where, $\mathrm{Gn}=$ Mycelial growth in normal

$$
\mathrm{Gt}=\text { Myclial growth in test }
$$

\section{RESULTS}

\section{Pharmacology}

Following pharmacological activities were performed on extracts of O. pes-caprae.

\section{Cytotoxic Bioassay}

In the current work Brine shrimp's lethality bioassay was conducted for knowing the cytotoxicity of ethanolic, methanolic, acetone, n-hexane and chloroform extractof $O$. pes-caprae. Three concentrations (10ppm,
$100 \mathrm{ppm}$, and $1000 \mathrm{ppm}$ ) were applied against brine shrimps. The extracts were found to produce dose dependent cytotoxicities, based on the following criteria

$30-40 \%$ lethality - Low activity

$50 \%$ lethality - moderate activity

60-70\% lethality -good activity

Above $70 \%$ lethality - significant activity

The highest significant cytotoxicity was shown by ethanolic extract which caused $100 \%\left(\mathrm{LD}_{50} 8.98\right)$ cytoxicity at $1000 \mathrm{ppm}$ followed by chloroform extract (93.33\%), n-hexane (90\%), methanol and acetone (86.66\%). OPE also showed significant effect at $100 \mathrm{ppm}$ i.e. $73.33 \%$. While at $10 \mathrm{ppm}$ and $100 \mathrm{ppm}$ all extracts depicted low to good activity. The result was shown in Table 2 and Figure 1.

\section{Phytotoxic Bioassay}

In the present work, the phytotoxic potential of crude ethanolic, methanolic, acetone, $\mathrm{n}$-hexane and chloroform extract of $O$. pes-caprae was evaluated by using Lemna minor. Three phytotoxic doses were used. The extract showed low to moderate level inhibitions of frond proliferation, w. r. $t$ following criteria (given below) used for phytotoxic potential 30-40\% inhibition: Low activity

$50 \%$ inhibition: moderate inhibition

60-70\% inhibition: good activity

Above $70 \%$ inhibition - significant activity

The effect of extract was dose dependent. The data was taken on fourth day and seventh day of experiment. On fourth day the significant effect was shown by chloroform extract at $1000 \mathrm{ppm}\left(76 \%, \mathrm{FI}_{50} 0.073\right)$. All other

Table 1: E-medium's composition.

\begin{tabular}{cc}
\hline Name of chemicals & $\mathrm{g} / \mathrm{L}$ \\
\hline Potassium dihydrogen phosphate $(\mathrm{KH} 2 \mathrm{PO} 4)$ & 0.68 \\
Potassium nitrate(KNO3) & 1.515 \\
Calcium nitrate $(\mathrm{Ca}(\mathrm{NO} 2) 2.4 \mathrm{H} 2 \mathrm{O})$ & 1.180 \\
Magnesium sulfate $(\mathrm{MgSO} 4.7 \mathrm{H} 2 \mathrm{O})$ & 0.492 \\
Boric acid $(\mathrm{H} 3 \mathrm{BO} 3)$ & 0.00286 \\
Manganous chloride $(\mathrm{MnCl} 2.4 \mathrm{H} 2 \mathrm{O})$ & 0.00362 \\
Ferric chloride $(\mathrm{FeCl} 2.4 \mathrm{H} 2 \mathrm{O})$ & 0.00540 \\
Zinc sulfate $(\mathrm{ZnSO} 4.5 \mathrm{H} 2 \mathrm{O})$ & 0.00022 \\
Copper sulfate $(\mathrm{CuSO} 4.5 \mathrm{H} 2 \mathrm{O})$ & 0.00022 \\
Sodium molybdate $(\mathrm{Na} 2 \mathrm{MO} 4.2 \mathrm{H} 2 \mathrm{O})$ & 0.00012 \\
Ethylene diamino tetra acetic acid $(\mathrm{EDTA})$ & 0.01120 \\
\hline
\end{tabular}

Table 2: Brine shrimp's lethality cytotoxic bioassay of ethanolic (OPE), methanolic (OPM), acetone (OPA), $n$-hexane (OPH) and

\begin{tabular}{|c|c|c|c|c|c|}
\hline \multirow[t]{2}{*}{ Treatment } & \multirow[t]{2}{*}{ No. of shrimps } & \multicolumn{3}{|c|}{ Percent mortality } & \multirow[t]{2}{*}{$\mathrm{LD}_{50}$} \\
\hline & & 10ppm & 100ppm & 1000ppm & \\
\hline Control (-) & 30 & - & - & - & \\
\hline OPE & 30 & $56.66 \pm 5.77$ & $73.33 \pm 5.77$ & $100 \pm 0.00$ & 8.98 \\
\hline OPM & 30 & $33.33 \pm 5.77$ & $53.33 \pm 5.77$ & $86.66 \pm 5.77$ & 48.14 \\
\hline OPA & 30 & $26.66 \pm 5.77$ & $36.66 \pm 5.77$ & $86.66 \pm 5.77$ & 96.58 \\
\hline $\mathrm{OPH}$ & 30 & $30.00 \pm 0.00$ & $40 \pm 10.00$ & $90 \pm 0.00$ & 30.96 \\
\hline OPC & 30 & $46.66 \pm 5.77$ & $53.33 \pm 5.77$ & $93.33 \pm 5.77$ & 21.25 \\
\hline
\end{tabular}
chloroform (OPC) extracts of Oxalis pes-caprae showing \% mortalities and $\mathrm{LD}_{50}$. 


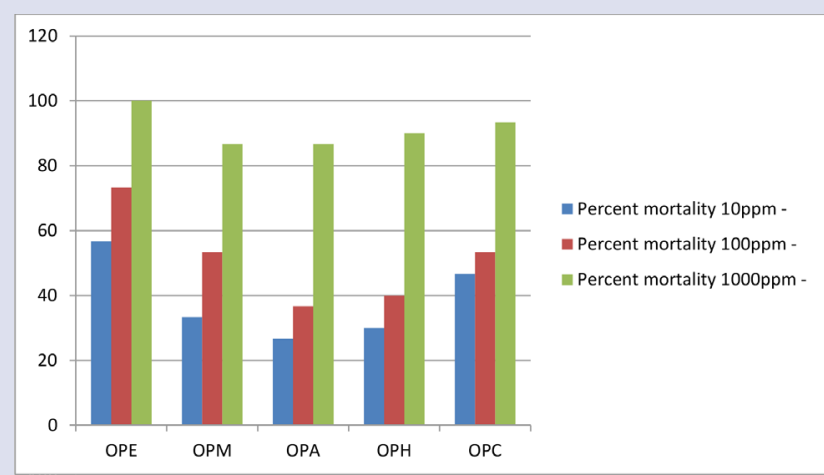

Figure 1: Brine shrimps lethality cytotoxic bioassay of ethanolic, methanolic, acetone, $\mathrm{n}$-hexane and chloroform extracts of Oxalis pes-caprae.

Table 3: Lemna phtotoxicity of ethanolic (OPE), methanolic (OPM), acetone (OPA), $n$-hexane (OPH) and chloroform (OPC) extract of Oxalis pes-caprae showing \% inhibition and $\mathrm{FI}_{50}$ after 3 days of experiment.

\begin{tabular}{ccccc}
\hline \multirow{2}{*}{ Treatment } & \multicolumn{3}{c}{ Percent growth inhibition } & \multirow{2}{*}{$\mathrm{FI}_{50}$} \\
\cline { 2 - 4 } & $10 \mathrm{ppm}$ & $100 \mathrm{ppm}$ & $1000 \mathrm{ppm}$ & \\
\hline Control (+) & $87.82 \pm 1.11$ & $87.82 \pm 1.11$ & $87.82 \pm 1.11$ & 0.0395 \\
OPE & $38.66 \pm 2.30$ & $52 \pm 4$ & $58.66 \pm 2.30$ & 421.9592 \\
OPM & $32 \pm 4$ & $46.66 \pm 6.11$ & $53.33 \pm 2.30$ & 367.3615 \\
OPA & $26.66 \pm 4.61$ & $34.66 \pm 2.30$ & $56 \pm 4$ & 551.9551 \\
OPH & $32 \pm 4$ & $44 \pm 4$ & $56 \pm 4$ & 319.1081 \\
OPC & $64 \pm 4$ & $72 \pm 4$ & $76 \pm 4$ & 0.073 \\
\hline
\end{tabular}

Table 4: Lemna phtotoxicity of ethanolic (OPE), methanolic (OPM), acetone (OPA), $n$-hexane (OPH) and chloroform (OPC) extract of Oxalis pes-caprae showing $\%$ inhibition and $\mathrm{FI}_{50}$ after $\mathbf{6}$ days of experiment.

\begin{tabular}{ccccc}
\hline \multirow{2}{*}{ Treatment } & \multicolumn{3}{c}{ Percent growth inhibition } & \multirow{2}{*}{$\mathrm{FI}_{50}$} \\
\cline { 2 - 4 } & $10 \mathrm{ppm}$ & $100 \mathrm{ppm}$ & $1000 \mathrm{ppm}$ & \\
\hline Control (+) & $87.82 \pm 1.11$ & $87.82 \pm 1.11$ & $87.82 \pm 1.11$ & 0.0395 \\
OPE & $62.66 \pm 2.30$ & $69.33 \pm 2.30$ & $84 \pm 4$ & 1.4229 \\
OPM & $49.33 \pm 6.11$ & $60 \pm 4$ & $86.66 \pm 2.30$ & 15.6293 \\
OPA & $42.66 \pm 15.14$ & $52 \pm 4$ & $69.33 \pm 2.30$ & 44.0706 \\
OPH & $56 \pm 4$ & $68 \pm 4$ & $68 \pm 4$ & 0.557 \\
OPC & $85.33 \pm 4.61$ & $90 \pm 6.11$ & $88 \pm 4$ & 0.073 \\
\hline
\end{tabular}

extracts showed low to good activity at 10ppm and 100ppm. On seventh day of experiment the significant inhibition was shown by chloroform extract at $100 \mathrm{ppm}$ which was $90 \%$ with $\mathrm{FI}_{50} 0.073$. The entire extracts showed moderate to significant activity at 10 and $1000 \mathrm{ppm}$. The results are summarized in Table 3 and 4, Figure 2 and 3.

\section{Antibacterial Activity}

For curing bacterial infections, anti-microbial activity gives chief basis. In current study ethanolic, methanolic, acetone, n-hexane and chloroform extract of O. pes-caprae against Xanthomonas, Clavibacter machengnitis and Bacillus at 100,1000, 1500 and 2500ppm were tested. All the extracts showed significant inhibition zone at $2500 \mathrm{ppm}$ against all bacterial strains. The highest inhibition was showed by ethanolic extract at

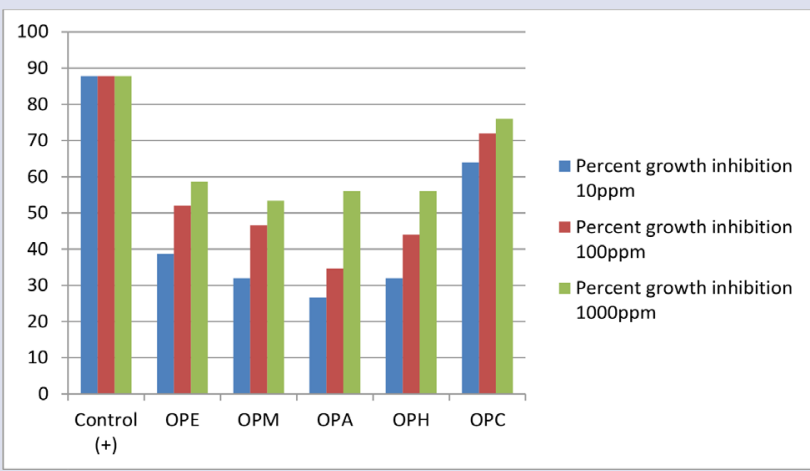

Figure 2: Lemna phtotoxicity of ethanolic, methanolic, acetone, $\mathrm{n}$-hexane and chloroform extract of Oxalis pes-caprae showing \% inhibition after 3 days of experiment.

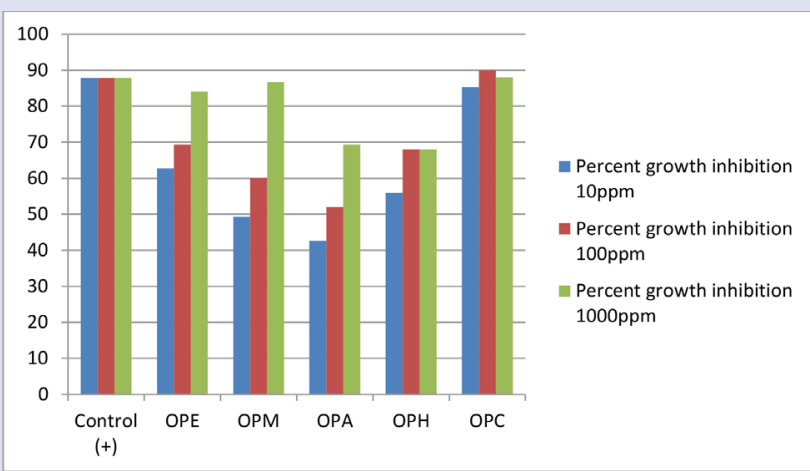

Figure 3: Lemna phtotoxicity of ethanolic, methanolic, acetone, n-hexane and chloroform extract of Oxalis pes-caprae showing \% inhibition after 6 days of experiment.

2500ppm against Xanthomonas, Clavibacter and Bacillus which were $16.25 \pm 0.353,17.75 \pm 0.35$ and $20.5 \pm 0.70$ respectively. At $100 \mathrm{ppm}$ the extracts showed low inhibition zone against strains which were 10 , $9.75 \pm 0.35,11$, respectively (Table 5, Figure 4).

\section{Antifungal Activity}

In the current work ethanolic, methanolic, acetone, n-hexane and chloroform extracts of $O$. pes-caprae were examined for antifungal potential against fungalstrains likeAspergillus flavus, Penicillium and Fusarium solani at 100 and 1000ppm. The results are presented in Table 6 and Figure 5. Ageneral trend of dose dependency was observed i.e. effect became more pronounced withincreasing concentration of the various tested samples. Ethanolic extract was found effective against $A$. flavus (48.24 $\pm 1.24 \%)$ followed by Fusarium solani $(41.5 \pm 0.70 \%)$ and Penicilliun $(35.34 \pm 0.98 \%)$ at $1000 \mathrm{ppm}$.

\section{DISCUSSION}

\section{Cytotoxic Bioassay}

Many researchers conducted the activity on different plants like Ali et al. ${ }^{21}$ (2009) analyzed root extracts of Euphorbia wallichii for cytotoxicity. Nisar et al. ${ }^{22}$ (2011) reported crude methanolic extract and various fractions from Zizyphus oxyphylla stem. Khuda et al. ${ }^{23}$ (2012) investigated the extracts from leaves of $X$. strumarium, Achyranthes aspera, Valeriana 
Table 5: Antibacterial activities of ethanolic, methanolic, acetone, $n$-hexane and chloroform extracs of Oxalis pes-caprae at different concentrations. All values are mean \pm SEM of 3 determination.

\begin{tabular}{|c|c|c|c|c|}
\hline \multirow{2}{*}{ Treatment } & \multirow{3}{*}{ Concentration } & \multicolumn{3}{|c|}{ Zone of inhibition (mm) } \\
\hline & & Xanthomonas & Clavibacter machengnitis & Bacillus \\
\hline DMSO (-) & & - & - & - \\
\hline \multirow[t]{2}{*}{ Streptomycin (+) } & $100 \mathrm{ppm}$ & $17.5 \pm 0.70$ & $18.75 \pm 0.35$ & $21.75 \pm 0.35$ \\
\hline & 100 ppm & $10 \pm 0.00$ & $9.75 \pm 0.35$ & $11 \pm 0.00$ \\
\hline \multirow{3}{*}{ OPE } & $1000 \mathrm{ppm}$ & $12.25 \pm 0.35$ & $12.25 \pm 0.35$ & $13.75 \pm 0.35$ \\
\hline & $1500 \mathrm{ppm}$ & $13.25 \pm 0.35$ & $13.75 \pm 0.35$ & $15.25 \pm 0.35$ \\
\hline & $2500 \mathrm{ppm}$ & $16.25 \pm 0.35$ & $17.75 \pm 0.35$ & $20.5 \pm 0.70$ \\
\hline \multirow{4}{*}{ OPM } & 100 ppm & $11 \pm 0.00$ & $9.5 \pm 0.00$ & $10.75 \pm 1.06$ \\
\hline & $1000 \mathrm{ppm}$ & $11.5 \pm 0.00$ & $12.75 \pm 0.35$ & $14.5 \pm 0.00$ \\
\hline & $1500 \mathrm{ppm}$ & $13.25 \pm 0.35$ & $13.75 \pm 0.35$ & $14.75 \pm 0.35$ \\
\hline & $2500 \mathrm{ppm}$ & $16 \pm 0.00$ & $17.75 \pm 0.35$ & $20.5 \pm 0.70$ \\
\hline \multirow{4}{*}{ OPA } & 100 ppm & $9.75 \pm 0.35$ & $9.0 \pm 0.00$ & $9.25 \pm 0.35$ \\
\hline & $1000 \mathrm{ppm}$ & $12.25 \pm 0.35$ & $12 \pm 0.00$ & $13.25 \pm 0.35$ \\
\hline & $1500 \mathrm{ppm}$ & $13 \pm 0.00$ & $13.25 \pm 0.35$ & $14.25 \pm 0.35$ \\
\hline & $2500 \mathrm{ppm}$ & $16.25 \pm 0.35$ & $16.75 \pm 1.06$ & $19.25 \pm 0.35$ \\
\hline \multirow{4}{*}{$\mathrm{OPH}$} & 100 ppm & $9.25 \pm 0.35$ & $9.5 \pm 0.00$ & $9 \pm 0.00$ \\
\hline & $1000 \mathrm{ppm}$ & $12.5 \pm 0.00$ & $12.25 \pm 0.35$ & $12.25 \pm 0.35$ \\
\hline & $1500 \mathrm{ppm}$ & $12.75 \pm 0.35$ & $1.25 \pm 0.35$ & $14.5 \pm 0.70$ \\
\hline & $2500 \mathrm{ppm}$ & $15.25 \pm 0.35$ & $15.25 \pm 0.35$ & $17.75 \pm 0.35$ \\
\hline \multirow{4}{*}{ OPC } & 100 ppm & $9.75 \pm 0.35$ & $9.75 \pm 0.35$ & $9 \pm 0.00$ \\
\hline & 1000 ppm & $11.25 \pm 0.35$ & $11.5 \pm 0.70$ & $11.25 \pm 0.35$ \\
\hline & $1500 \mathrm{ppm}$ & $13 \pm 0.00$ & $13.75 \pm 1.06$ & $14.25 \pm 0.35$ \\
\hline & $2500 \mathrm{ppm}$ & $14.25 \pm 0.35$ & $15.5 \pm 0.70$ & $16.5 \pm 0.70$ \\
\hline
\end{tabular}

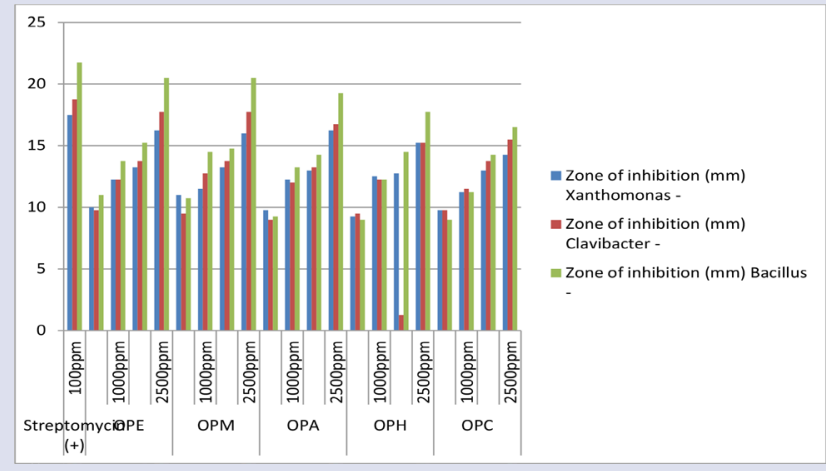

Figure 4: Antibacterial activities of ethanolic, methanolic, acetone, $\mathrm{n}$-hexane and chloroform extracts of Oxalis pes-caprae at different concentrations.

wallichii and roots of Duchesnea indica for cytotoxic activity.Our study is in line with these workers.

\section{Phytotoxic Bioassay}

Hameed et $a .^{24}$ (2013) evaluated methanolic and acetone extracts of the Withaniasomnifera, Datura innoxia, Solanum surattense, Withania coagulans and Solanum nigrumfor phytotoxicity. Shah et al. ${ }^{25}$ (2013) demonstrated crude methanolic extract and solvent fractions of Conyza

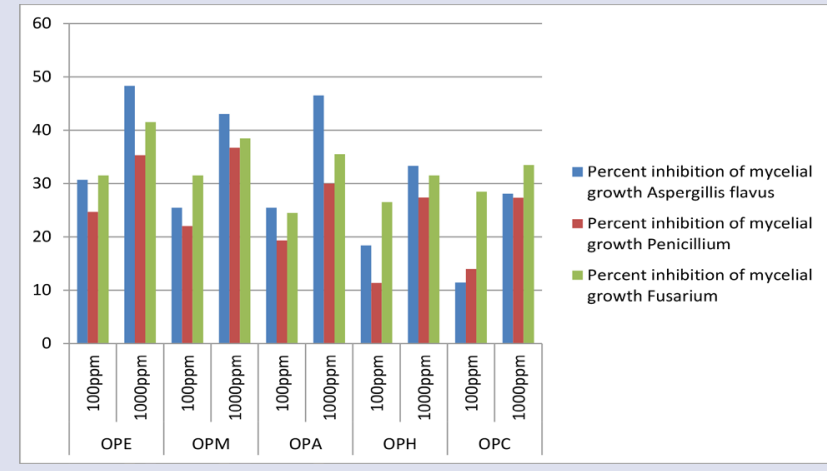

Figure 5: Antifungal activities of ethanolic, methanolic, acetone, $\mathrm{n}$-hexane and chloroform extracts of Oxalis pes-caprae at different concentrations.

bonariensisfor the phytotoxicity. Rehmanullah et al. ${ }^{26}$ (2014) performed phytotoxic activity on Euphorbia helioscopa and Euphorbia hirta. These all workers have carried out similar studies which strengthen the present findings.

\section{Antibacterial Activity}

Various other workers have also conducted such studies on various plants, e.g., Hafeez et al. ${ }^{27}$ (2014) reported antibacterial activity of 
Naila and Ibrar: Pharmacological Studies of Oxalis Pes-caprae L.

Table 6: Antifungal activities of the ethanolic, methanolic, acetone, $n$-hexane and chloroform extracs of $O x a$ lis pes-caprae at different concentrations. All values are mean \pm SEM of 3 determination.

\begin{tabular}{ccccc}
\hline Treatment & Concentration & \multicolumn{3}{c}{ Percent inhibition of mycelial growth } \\
\cline { 3 - 5 } & & Aspergillis flavus & Penicillium & Fusarium solani \\
\hline OPE & $100 \mathrm{ppm}$ & $30.69 \pm 1.23$ & $24.66 \pm 0.94$ & $31.5 \pm 0.70$ \\
& $1000 \mathrm{ppm}$ & $48.24 \pm 1.24$ & $35.3 \pm 0.98$ & $41.5 \pm 0.70$ \\
OPM & $100 \mathrm{ppm}$ & $25.43 \pm 1.23$ & $21.99 \pm 0.94$ & $31.5 \pm 0.70$ \\
& $1000 \mathrm{ppm}$ & $42.97 \pm 1.23$ & $36.66 \pm 0.94$ & $38.5 \pm 0.70$ \\
OPA & $100 \mathrm{ppm}$ & $25.43 \pm 1.23$ & $19.33 \pm 0.94$ & $24.5 \pm 0.70$ \\
& $1000 \mathrm{ppm}$ & $46.48 \pm 1.23$ & $29.99 \pm 0.94$ & $35.5 \pm 0.70$ \\
OPH & $100 \mathrm{ppm}$ & $18.41 \pm 1.23$ & $11.33 \pm 0.94$ & $26.5 \pm 0.70$ \\
& $1000 \mathrm{ppm}$ & $33.32 \pm 2.48$ & $27.33 \pm 0.94$ & $31.5 \pm 0.70$ \\
OPC & $100 \mathrm{ppm}$ & $11.4 \pm 1.24$ & $13.99 \pm 0.94$ & $28.5 \pm 0.70$ \\
& $1000 \mathrm{ppm}$ & $28.06 \pm 2.48$ & $27.3 \pm 0.98$ & $33.5 \pm 0.70$ \\
\hline
\end{tabular}

Eruca sativa, Bombax malabaricum, Chorisia speciosa,Bauhinia variegate, Kigelia Africana, Nigella sativa, Pinus halepensis, Zingiber officinale, Piper nigrum, Albizzia lebbeck, Ceiba pentandra, Origanum majorana, Rosmarinus officinalis, Ocimum basilicum, Thymus vulgaris, Mentha piperita, Simmondsia chinensis, Linum usitatissimum, Pimpinella anisum and Brachychiton opulneus. All extracts exhibited significant effect. He concluded that best aqueous extract was from A. lebbeck. Madureira et $a .^{28}$ (2014) determined the antimicrobial potential of Sanguisorba hybrid. All extracts were tested againstyeast Candida albicans, Gramnegative (Salmonella typhimurium, Klebsiella pneumonia, Pseudomonas aeruginosa,) Gram-positive (Staphylococcus aureus, Staphylococcus epidermidis, Mycobacterium smegmatis, Enteroccocus faecalis). Our study is in line with these workers.

\section{Antifungal Activity}

Similar antifungal investigations were performed by several workers on various plants. Khan et al. ${ }^{29}$ (2011) worked out antifungal activity of Adhatoda vasica, Viburnum cotinifolium, Vitex negundo, Peganum harmala,Mimosa rubicaulis, Broussonetia papyrifera, Chenopodium ambrosoides, Euphorbia hirta, Taraxacum officinale, Urtica dioica, Verbascum Thapsus, Caryopteris grata and Woodfordia fruiticosa, Nisar et al. ${ }^{22}$ (2011) performed antifungal activity on crude methanolic extract and different fractions from Zizyphus oxyphylla stem against 5 fungal strainsviz., Aspergilus flavus, Fusarium solani, Microsporum canis, Candidaglaberataand Candida albicans. Shah et al. ${ }^{25}$ (2013) analyzedConyza bonariensisfor antifungal activity. Our study is in line with these workers.

\section{CONCLUSION AND RECOMMENDATION}

In $O$. pes-caprae highest significant cytotoxicity was shown by ethanolic extract at 1000 ppm with $\mathrm{LD}_{50} 8.98$ which revealed this plant contains a good cytotoxic compound. The highest significant phytotoxicity was shown by chloroform extract at 1000 ppm with $\mathrm{FI}_{50} 0.1048$ which depicted that this plant contains a natural weedicide character. The highest antibacterial activity was shown by ethanolic extract against Xanthomonas, Clavibacter machengnitisand Bacillus which was $16.25 \pm 0.353,17.75 \pm 0.35$, $20.5 \pm 0.70$. The highest antifungal activity was shown by ethanolic extract against $A$. flavus ( $48.24 \pm 1.24 \%)$ followed by Fusarium solani ( $41.5 \pm 0.70 \%)$ and Penicilliun ( $35.34 \pm 0.98 \%$ ) at $1000 \mathrm{ppm}$. It can be concluded that this plant is a natural antibacterial and antifungal. Pharmacological potentials like cytotoxic, phytotoxic, antibacterial and antifungal activities of plants showed that these plants can be used in upcoming time for extracting numerous active constituents for their pharmacological preparations.
These results might be exploited as cheaper effectual remedies for different ailments.

\section{CONFLICT OF INTEREST}

The authors declare no conflict of interest.

\section{SUMMARY}

In present study Oxalis pes-caprae belonging to family oxalidaceae evaluated for pharmacological activities like cytotoxicity, phtotoxicity, antibacterial and antifungal bioassays. Its ethanolic extract showed highly significant (100\%) cytotoxicity with $\mathrm{LD}_{50} 8.98$ at $1000 \mathrm{ppm}$. Lemna minor phytotoxicity asssay showed that O. pes-caprae chloroform extract showed $90 \%$ inhibition at 1000 ppm with $\mathrm{FI}_{50}$ 0.1048. Antibacterial bioassays showed that all the samples of the plant were significant against Xanthomonas, Clavibacter machengnitis and Bacillus at 1000, 1500 and 2500 ppm doses. Dose dependent antifungal activities against test species (Aspergillus flavus, Penicillium and Fusarium solani) were noticed for all the extracts at 100 and $1000 \mathrm{ppm}$. Pharmacological potentials showed that this plant can be used in upcoming time for extracting numerous active constituents for their pharmacological preparations.

\section{ABBREVIATIONS}

OPE: Oxalis pes-caprae ethanol; OPM: Oxalis pes-caprae methanol; OPA: Oxalis pes-capra eacetone; OPH: Oxalis pes-caprae n-hexane; OPC: Oxalis pes-caprae chloroform.

\section{REFERENCES}

1. Balunas MJ, Kinghorn AD. Drug discovery from medicinal plants. Life Sci. 2005;78(5):431-41.

2. Blondeau QTD, SciorT, Bernard P, Morin-Allory L. Reverse pharmacognosy: another way to harness the generosity of nature. Curr Pharm Des. 2010;16(15):1682-96.

3. Rezuan SB. Macro and micro morphological characterization of Jackia ornate. University Teknologi Mari (UiTM). 2010.

4. Awang D. Feverfew products. Can Med Assoc J. 1997;157(5):510-20.

5. Meyer BN, Ferrigni NR, Putnam JE, Jacobsen LB, Nichols DE, McLaughlin JL. Brine shrimp: aconvenient general bioassay for active plant constituents. Planta Med. 1982;45(5):31-4.

6. Andereson JE, Goetz CM, McLaughlin JE, Suffness M. Ablind comparison of simple bench-top bioassaysand human cell cytotoxicities as antitumor prescreens. Phytochem. Anal. 199;2(3):107-11.

7. Atta-ur-Rehman. Studies in Natural Product Chemistry, Netherlands. Elsevier Science Publishers. 1991;9:383-09.

8. Nascimento GF, Locatelli J, Freitas PC, Silva GL. Antibacterial activity of plant extracts and phytochemicals on antibiotic-resistant bacteria. Braz J Microbiol. 
2000;31(4):247-56.

9. Harris CA, Renfrew MJ, Woolridge MW. Assessing the risk of pesticide residues to consumers: recent and future developments. Food Addit Contam. 2001;18(12):1124-9.

10. Nasir Y. Flora of Pakistan. Department of Botany, University of Karachi: Karachi. 1971;4:1-3.

11. Villiers SJA. Cook and Enjoy. NB Publishers. 2010.

12. Mitchell WJ, Wijk BB, Gerdina M. The medicinal and poisonous plants of Southern and Eastern Africa. 2nd ed Pub. E and S Livingstone. 1962.

13. Tortorello M. "A New Generation Discovers Grow-lt-Yourself Dyes". The New York Time. 2012.

14. Zhongyao LI, Yingzi HE, Xuejing Ql. Research progress of biological activities of oxalis. Medicinal Plant. 2014;5(10):1-3,6.

15. Atta-ur-Rehman, Choudhary MI, Thomsen WJ. Bioassay Technique for Drug Development Harwood Academic Publishers. 2001.

16. Barkatullah, Ibrar M, Muhammad N. Evaluation of Zanthoxylum armatumDC for in-vitro and in-vivo pharmacological screening. Afr J Pharm and Pharmacol. 2011;5(14):1718-23.

17. Rathan A. Antimicrobials in laboratory medicine. BI Churchill Livingstone Pvt Ltd, New Delhi. 2000;194-03.

18. Perez C, Paul M, Bezique P. Alta biomed. Group Experiences. 1990;105-13.

19. Umadevi S, Mohanta GP, Chelladurai V, Manna PK, Manavalan R. Antibacterial and antifungal activity of Andrographis echiodes. J Nat Remedies. 2003;3(2):185-8.
20. Ali-Shtayeh MS, Suheil AG. Antifungal activity of plants extracts against dermatophytes. Mycoses.1999;42(11-12):665-72.

21. Ali I, Naz R, Khan WN, Gul R, Choudary MI. Biological screening of different root extracts of Euphorbia wallichii. Pak J Bot. 2009;41(4):1737-41.

22. Nisar M, Kaleem WA, Qayum M, Marwat IK,Zia-UI-Haq M, Ali I, et al. Biological screening of Zizyphus oxyphylla Edgew stem. Pak J Bot. 2011;43(1):311-7.

23. Khuda F, Iqbal Z, Zakiullah, Khan A, Nasir F, Muhammad N, et al,. Metal analysis, phytotoxic, insecticidal and cytotoxic activities of selected medicinal plants of Khyber Pakhtunkhwa. Pak J Pharm Sci. 2012;25(1):51-8.

24. Hameed I, Hussain F, Sher Z, Bacha N, Khan AA. Cytotoxicity and phytotoxicity of some medicinal plants of family solanaceae. Pak J Bot. 2013;45(5):1749-54.

25. Shah NZ, Muhammad N, Azeem S, Khan AZ, Muhammad S, Khan H. Antimicrobial and phytotoxic properties of Conyza bonariensis. Pharm Res. 2013;1(1):8-11.

26. Rehmanullah, Din S, Shah S, Muhammad Z. Pharmacological evaluation of Euphorbia helioscopia L. and Euphorbia hirta. Int J Biosci. 2014;4(1):20-6.

27. Hafeez EYA, Nguyen TN, Karamova NS, Ilinskaya ON. Antibacteial activity of certain medicinal plants on different bacterial strains associated with colorectral cancer. Int J Biosci. 2014;5(7):219-29.

28. Madureira AM, Duarte A, Correia Al, Teixeira G.Sanguisorba hybrida: pharmacognostic studies and antimicrobial activity. Revista de Ciencias Agrarias. 2014;37(4):482-90.

29. Khan AM, Qureshi RA, Gillani SA, Ullah F. Antimicrobial activity of selected medicinal plants of Margalla Hills, Islamabad, Pakistan. J Med Plants Res. 2011;5(18):4665-70.

Cite this article: Naila S, Ibrar M. Pharmacological Studies of Oxalis Pes-caprae L. Pharmacog J. 2018;10(4):705-11. 